\title{
Research on the Equalization Level of Basic Public Services in Heilongjiang Province
}

\author{
Xiaofeng Zhang ${ }^{* 1}$, Shumin Yang ${ }^{1}$ \\ ${ }^{1}$ School of Finance and Public Administration, Harbin University of Commerce, Harbin, Heilongjiang 150028, China
}

\begin{abstract}
As an important link in the development of urban-rural integration, equalization of basic public services in urban and rural areas is the foundation of urban-rural integration and an important aspect of improving the quality of life of urban and rural residents. To understand the level of equalization of basic public services in urban and rural areas, it is necessary to reasonably measure the level of equalization of basic public services. This article constructs an evaluation system for the equalization of basic public services in urban and rural areas from the four dimensions of public education, social security, medical and health, and infrastructure. The entropy method is used to obtain the equalization index of basic public services in Heilongjiang Province. On this basis, a comprehensive analysis of the equalization of basic public services in the integrated development of urban and rural areas is carried out and corresponding policy recommendations are put forward.
\end{abstract}

\section{Introduction}

Urban-rural integration is the main way to deal with the relationship between workers and farmers and to solve the problem of balanced development between urban and rural areas in the new era. Promoting the equalization of basic public services is the content that the equalization of basic public services provides in a balanced manner in urban and rural areas, and it is also a basic link in the integrated development of urban and rural areas ${ }^{[1-2]}$. This paper takes the equalization of basic public services in urban and rural areas in Heilongjiang Province as the research object, constructs an index evaluation system for the equalization of basic public services in urban and rural areas, and measures the level of equalization of basic public services in urban and rural areas in Heilongjiang Province. Empirical methods are used to analyze the problems and shortcomings of the equalization of basic public services in Heilongjiang Province, and put forward corresponding solutions, in order to provide references for the equalization of basic public services in promoting the integration of urban and rural development in Heilongjiang Province.

\section{Measurement of the Equalization Level of Basic Public Services in Urban and Rural Areas}

\subsection{Selection and construction of index system}

For the construction of the indicator system for the equalization of basic public services in urban and rural areas, it is necessary to comprehensively consider the availability of data and the objectivity of the indicator system to reflect the level of equalization of basic public services. Based on the research of the existing literature on the construction of indicators, this article evaluates the level of equalization of basic public services in Heilongjiang Province from four aspects: basic public education, basic social security and employment, basic medical and health, and infrastructure.

The constructed index system is shown in Table 1.

Table 1. Index evaluation system.

\begin{tabular}{|c|c|c|}
\hline $\begin{array}{l}\text { First-level } \\
\text { indicators }\end{array}$ & $\begin{array}{l}\text { second-level } \\
\text { indicators }\end{array}$ & Three-level indicators \\
\hline \multirow{12}{*}{$\begin{array}{l}\text { Urban and } \\
\text { Rural Basic } \\
\text { Public } \\
\text { Service } \\
\text { Equalization } \\
\text { Index }\end{array}$} & \multirow{4}{*}{$\begin{array}{l}\text { Public } \\
\text { Education } \\
\text { Index }\left(A_{1}\right)\end{array}$} & $\begin{array}{l}\text { Educational expenditure per middle } \\
\text { School Student }\left(\mathrm{x}_{1}\right)\end{array}$ \\
\hline & & $\begin{array}{l}\text { Educational expenditure per pupil } \\
\left(\mathrm{x}_{2}\right)\end{array}$ \\
\hline & & $\begin{array}{l}\text { Middle school teacher-student ratio } \\
\left(\mathrm{x}_{3}\right)\end{array}$ \\
\hline & & $\begin{array}{l}\text { Primary school teacher-student ratio } \\
\left(\mathrm{x}_{4}\right)\end{array}$ \\
\hline & \multirow{3}{*}{$\begin{array}{l}\text { Social Security } \\
\text { Index }\left(A_{2}\right)\end{array}$} & $\begin{array}{l}\text { Basic pension insurance expenditure } \\
\text { per capita }\left(\mathrm{x}_{5}\right)\end{array}$ \\
\hline & & $\begin{array}{l}\text { Basic medical insurance coverage } \\
\left(\mathrm{x}_{6}\right)\end{array}$ \\
\hline & & Proportion of employed persons $\left(\mathrm{x}_{7}\right)$ \\
\hline & \multirow{3}{*}{$\begin{array}{l}\text { Health index } \\
\left(\mathrm{A}_{3}\right)\end{array}$} & $\begin{array}{l}\text { Number of beds in medical } \\
\text { institutions per } 10,000 \text { people }\left(x_{8}\right)\end{array}$ \\
\hline & & $\begin{array}{l}\text { Number of health technicians per } \\
10,000 \text { people }\left(x_{9}\right)\end{array}$ \\
\hline & & $\begin{array}{l}\text { Number of physicians per } 10,000 \\
\text { people }\left(\mathrm{x}_{10}\right)\end{array}$ \\
\hline & \multirow{2}{*}{$\begin{array}{l}\text { Infrastructure } \\
\text { Index }\left(\mathrm{A}_{4}\right)\end{array}$} & Water penetration rate $\left(\mathrm{x}_{11}\right)$ \\
\hline & & Gas penetration rate $\left(\mathrm{x}_{12}\right)$ \\
\hline
\end{tabular}

\subsection{Standardization of indicators}

Since the data types of different indicators are different, in order to eliminate the influence of the dimension on the

\footnotetext{
" Corresponding author: Xiaofeng Zhang: (1984-) Associate Professor, Master's Tutor, zhxf928@163.com.
} 
equalization index, the data needs to be standardized. Considering that this article studies the degree of equalization of urban and rural areas, the method of comparing rural indicators with urban indicators is used to standardize the indicators to determine the urban and rural basic public service equalization index.

If the standardized data is 0 , it means that rural areas have not enjoyed any basic public services; if the standardized data is 1 or greater, it means that rural areas enjoy at least the same public services as urban areas.

\subsection{Determination of indicator weight}

There are many methods for determining index weights in existing research, mainly subjective weighting methods including Delphi method and analytic hierarchy process, and objective weighting methods including factor analysis method and entropy method. Considering that the subjective weighting method relies more on the experience of experts and does not have objectivity, it may cause serious deviations in the results. Therefore, this article chooses the entropy method to determine the index weights.

Entropy was originally a thermodynamic concept. The entropy method is an information management method used by entropy in system theory. The weight of the index can be determined according to the degree of difference between the various index values of the evaluation system. The entropy value is a measure of uncertainty. The larger the entropy value, the more chaotic the system and the less useful information it can provide, so the index weight is also smaller.

The steps of entropy method to determine the index weight are as follows:

Let $\mathrm{x}_{\mathrm{ij}}$ be the observed value of the $\mathrm{j}$-th index in the $\mathrm{i}$ th evaluation object. $(i=1,2, \ldots, n ; j=1,2, \ldots, m)$

Calculate the index value ratio of the $\mathrm{i}$-th evaluated object on the $\mathrm{j}$-th evaluation index.

$$
P_{i j}=\frac{x_{i j}}{\sum_{i=1}^{n} x_{i j}}
$$

Calculate the entropy value of the $\mathrm{j}$-th evaluation index.

$$
e_{j}=-\frac{1}{\ln n} \sum_{i=1}^{n} p_{i j} \ln \left(p_{i j}\right)
$$

Calculate the difference coefficient $g_{j}$ of the evaluation index $\mathrm{x}_{\mathrm{j}}$.

$$
g_{j}=1-e_{j}
$$

Determination of weight.

$$
w_{2 j}=g_{j} / \sum_{j=1}^{m} g_{j}, j=1,2, \ldots, m
$$

The entropy value, difference coefficient and weight of the index obtained by the entropy method are shown in Table 2.

Table 2. Weight obtained by entropy method.

\begin{tabular}{|c|c|c|c|}
\hline Index & $\mathbf{e}_{\mathbf{j}}$ & $\mathbf{g}_{\mathbf{j}}$ & $\mathbf{w}_{\mathbf{j}}$ \\
\hline $\mathrm{x} 1$ & 0.99941 & 0.00059321 & 0.03728 \\
\hline $\mathrm{x} 2$ & 0.99979 & 0.000214368 & 0.01347 \\
\hline $\mathrm{x} 3$ & 0.99814 & 0.001863944 & 0.11714 \\
\hline $\mathrm{x} 4$ & 0.9994 & 0.000598119 & 0.03759 \\
\hline
\end{tabular}

\begin{tabular}{|c|c|c|c|}
\hline $\mathrm{x} 5$ & 0.99729 & 0.002714909 & 0.17061 \\
\hline $\mathrm{x} 6$ & 0.99655 & 0.003447049 & 0.21662 \\
\hline $\mathrm{x} 7$ & 0.99894 & 0.001060235 & 0.06663 \\
\hline $\mathrm{x} 8$ & 0.99862 & 0.001379418 & 0.08669 \\
\hline $\mathrm{x} 9$ & 0.99991 & 0.000092098 & 0.00579 \\
\hline $\mathrm{x} 10$ & 0.99941 & 0.000590081 & 0.03708 \\
\hline $\mathrm{x} 11$ & 0.99994 & 0.000061269 & 0.00385 \\
\hline $\mathrm{x} 12$ & 0.99670 & 0.003297951 & 0.20725 \\
\hline
\end{tabular}

\section{Data sources and empirical results}

\subsection{Data Sources}

The original data related to this article comes from the China Education Expenditure Statistical Yearbook, China Education Statistics Yearbook, China Statistics Yearbook, China Health Statistics Yearbook, Urban and Rural Construction Statistical Yearbook from 2009 to 2019. Some of these data are adjusted according to changes in the statistical caliber.

The statistical description of each indicator data after the actual data is standardized is shown in Table 3.

Table 3. Statistical description of indicator data.

\begin{tabular}{|c|c|c|c|c|}
\hline & Mean & sd & Min & Max \\
\hline $\mathrm{x} 1$ & 0.98546 & 0.053802 & 0.8781 & 1.0314 \\
\hline $\mathrm{x} 2$ & 1.11069 & 0.036809 & 1.0612 & 1.1666 \\
\hline $\mathrm{x} 3$ & 1.11056 & 0.108826 & 0.9738 & 1.2772 \\
\hline $\mathrm{x} 5$ & 0.03805 & 0.004525 & 0.0315 & 0.0461 \\
\hline $\mathrm{x} 6$ & 1.00529 & 0.133499 & 0.8498 & 1.1936 \\
\hline $\mathrm{x} 7$ & 0.95308 & 0.070835 & 0.8904 & 1.0883 \\
\hline $\mathrm{x} 8$ & 0.36576 & 0.031157 & 0.3356 & 0.4286 \\
\hline $\mathrm{x} 9$ & 0.42413 & 0.009202 & 0.4118 & 0.4384 \\
\hline $\mathrm{x} 10$ & 0.48756 & 0.026911 & 0.4474 & 0.5417 \\
\hline $\mathrm{x} 11$ & 0.89334 & 0.015849 & 0.8788 & 0.9195 \\
\hline $\mathrm{x} 12$ & 0.27796 & 0.0352 & 0.2041 & 0.3069 \\
\hline
\end{tabular}

\subsection{Empirical analysis results}

According to the constructed index system and the weights obtained, we can get the Heilongjiang Province urban and rural basic public service equalization level index, and then judge the Heilongjiang Province basic public service equalization level in the process of urbanrural integration development. The weighted summation method is used to evaluate the equalization index of urban and rural basic public services by combining the standardized values of various indicators and the corresponding weights.

The closer the obtained index is to 1 , the higher the level of equalization of basic public services in urban and rural areas, which also indicates that the level of urbanrural integration development is high; the closer the obtained index is to 0 , the lower the level of equalization of basic public services in urban and rural areas, which also indicates that the level of urban-rural integration development is low. 
The calculation of the equalization index of urban and rural basic public services in this article is based on the following formula:

$$
S=\sum_{j=1}^{m} w_{j} \times x_{i j}
$$

When calculating the equalization index of each basic public service, the weighted summation method of the standardized value of each indicator and the corresponding secondary indicator weight is used to obtain the equalization level. The index of each service and the composite index of the equalization of basic public services are shown in Table 4.

Table 4. Results of equalization of basic public services in urban and rural areas.

\begin{tabular}{|c|c|c|c|c|c|}
\hline Year & $\begin{array}{c}\text { Public } \\
\text { Educat } \\
\text { ion } \\
\text { Equali } \\
\text { zation } \\
\text { Index }\end{array}$ & $\begin{array}{c}\text { Social } \\
\text { Securit } \\
\mathbf{y} \\
\text { Equali } \\
\text { zation } \\
\text { Index }\end{array}$ & $\begin{array}{c}\text { Medic } \\
\text { al and } \\
\text { Health } \\
\text { Equali } \\
\text { zation } \\
\text { Index }\end{array}$ & $\begin{array}{c}\text { Infrastr } \\
\text { ucture } \\
\text { Equaliz } \\
\text { ation } \\
\text { Index }\end{array}$ & $\begin{array}{c}\text { Equali } \\
\text { zation } \\
\text { Index } \\
\text { of } \\
\text { Basic } \\
\text { Public } \\
\text { Servic } \\
\text { es }\end{array}$ \\
\hline 2009 & 1.0270 & 0.5782 & 0.3786 & 0.2168 & 0.5777 \\
\hline 2010 & 1.0170 & 0.5921 & 0.3801 & 0.2469 & 0.5874 \\
\hline 2011 & 1.1013 & 0.6190 & 0.3949 & 0.3159 & 0.6251 \\
\hline 2012 & 1.0884 & 0.6549 & 0.4063 & 0.3173 & 0.6405 \\
\hline 2013 & 1.2479 & 0.6961 & 0.4117 & 0.3106 & 0.6913 \\
\hline 2014 & 1.2310 & 0.7131 & 0.3967 & 0.3058 & 0.6925 \\
\hline 2015 & 1.1960 & 0.6928 & 0.3862 & 0.3065 & 0.6749 \\
\hline 2016 & 1.1736 & 0.6714 & 0.3923 & 0.3174 & 0.6637 \\
\hline 2017 & 1.0877 & 0.5626 & 0.3710 & 0.2796 & 0.5859 \\
\hline 2018 & 1.0919 & 0.5601 & 0.3778 & 0.2751 & 0.5856 \\
\hline
\end{tabular}

\section{Analysis on the Equalization Level of Basic Public Services in Heilongjiang Province}

\subsection{Analysis on the Equalization Level of Public Education in Urban and Rural Areas}

The level of equalization of urban and rural public education in Heilongjiang Province is generally high. From 2009 to 2018, the equalization index of urban and rural public education in Heilongjiang Province was above 1 in most years, ranking among the top of other indicators.

In terms of education expenditure per student, in 20092018, the ratio of rural per student education expenditure to urban per student education expenditure gradually increased, indicating that the education expenditure for each rural student was more than that for urban students, which resulted in the urban and rural public education index being higher than other indicators. In terms of the ratio of urban and rural teachers to students, the number of teachers per student in both urban and rural areas in Heilongjiang province is very low, and each teacher is responsible for at least 10 students. However, the situation in rural areas is better than that in urban areas. The reason why the teacher-student ratio in rural areas is higher than that in urban areas is that there are more teachers in rural areas. However, an important reason for the decline in the ratio of urban-rural teachers to students after 2013 was also due to the decline in the number of teachers in rural areas, which also led to a decline in the urban and rural public education equalization index.

Therefore, to achieve the equal development of public education in urban and rural areas, it is necessary to retain rural teacher resources and attract more outstanding teachers to teach in rural areas ${ }^{[3]}$.

\subsection{Analysis on the Equalization Level of Social Security in Urban and Rural Areas}

The level of equalization of urban and rural social security in Heilongjiang Province is relatively good. The urban and rural equalization index of social security and employment has stabilized above 0.5 from 2009 to 2018 . Although there has been a downward trend in some years, the social security equalization index is higher than the equalization index of health care and infrastructure as a whole.

In terms of per capita pension insurance, the gap between urban and rural areas in Heilongjiang Province is very large. Compared with urban areas, rural per capita pension insurance accounts for less than $10 \%$ of urban areas. By comparing the number of employed persons in urban and rural areas, it can be found that before 2011, there were more employed persons in rural areas than in urban areas. As the total population of Heilongjiang Province has shrunk and the economy has grown, the number of employed persons in rural areas has gradually decreased while the number of employed persons in urban areas has increased slightly, resulting in a continuous decrease in the ratio of employed persons in urban and rural areas. In terms of basic medical insurance coverage, due to the comprehensive promotion of the new rural cooperative medical insurance, the level of equalization of urban and rural basic medical insurance will rise steadily before 2016. However, after the urban residents' basic medical insurance was integrated with the new rural cooperative medical insurance in 2016, the coverage of basic medical insurance in rural areas declined due to the elimination of some people who had repeatedly participated in the insurance.

Therefore, it is necessary to improve rural social security and employment, so that the development of the countryside will be more competitive under the conditions of economic development and the declining working population, and attract more laborers to work in the countryside ${ }^{[4]}$.

\subsection{Analysis on the level of equalization of medical and health in urban and rural areas}

The level of equalization of urban and rural health care in Heilongjiang Province is relatively low. From 2009 to 2018, the urban and rural medical and health equalization index was roughly 0.4 , and it has shown a downward trend in recent years, indicating that Heilongjiang Province 
needs to further improve the medical and health conditions in rural areas in order to achieve equalization of urban and rural medical and health.

Observation shows that the actual data of various medical and health indicators is increasing year by year, but due to the faster growth of urban areas, the urban-rural equalization index decreases slightly. Therefore, this article believes that Heilongjiang's urban and rural medical and health equalization is generally low, and there has been an urban bias in the development process, which has led to a further expansion of the urban-rural medical and health gap. To achieve the equalization of medical and health care in urban and rural areas, we must improve the overall medical and health level while not neglecting the importance of rural medical and health standards for the development of urban and rural integration, and increase the improvement of medical and health in rural areas.

\subsection{Analysis of the level of equalization of infrastructure in urban and rural areas}

The level of equalization of urban and rural infrastructure in Heilongjiang Province is relatively poor. From 2009 to 2018, the urban and rural infrastructure equalization index fluctuated at the level of 0.3 , which was at a low level among the basic public service equalization indexes. It shows that to improve the level of equalization of urban and rural infrastructure, more attention and investment from financial departments are needed to achieve balanced urban and rural development of infrastructure.

From the perspective of water penetration rate and gas penetration rate, there is a large gap in the degree of equalization of infrastructure in Heilongjiang Province. In terms of water penetration rate, although the water penetration rate in rural areas is still lower than the urban water penetration rate, the gap between the two is relatively small, and both urban and rural water supplies have been well supplied. As for the gas penetration rate in urban and rural areas, it can be found that the gas penetration rate in rural areas is significantly lower than that in urban areas.

Therefore, the reason for the low equalization index of urban and rural infrastructure in Heilongjiang Province is because the level of infrastructure in rural areas is still at a lower level than that in cities, and there are no conditions for achieving urban-rural integration.

\subsection{Analysis on the Equalization Level of Basic Public Services in Urban and Rural Areas}

The level of equalization of basic public services in urban and rural areas is derived from the level of equalization in the four dimensions of public education, social security, health care, and infrastructure, reflecting the overall level of equalization of basic public services in urban and rural areas in Heilongjiang Province.

Through empirical analysis of data, it can be obtained that the equalization index of urban and rural basic public services in Heilongjiang Province is roughly 0.6, and there is no obvious upward or downward trend with the change of the year. It shows that although the actual data on all aspects of basic public services in Heilongjiang Province are gradually increasing with the development of the economy, the level of equalization of basic public services in urban and rural areas has not been significantly improved. To achieve the equalization of basic public services in urban and rural areas, it is necessary not only to increase financial investment in the supply of basic public services, but also to improve the level of equalization of basic public services in a targeted manner based on urban and rural conditions ${ }^{[5]}$.

\section{Conclusion}

The equalization of basic public services in urban and rural areas is an important part of the development of urban and rural integration. Only when urban and rural residents enjoy equalized basic public services and their basic rights to survive and develop are guaranteed, can a good situation of mutual promotion and common development between urban and rural areas be realized.

Based on the analysis of the level of equalization of basic public services in urban and rural areas, it is concluded that in order to increase the level of equalization of basic public services in urban and rural areas, we must first increase financial investment and increase sufficient capital guarantee for the equalization of basic public services. Secondly, we must also pay attention to the supply of basic public services in rural areas, so that farmers can enjoy more and better basic public services. Finally, developing the rural economy is also a means to fundamentally improve the level of rural public services.

Fund project: Heilongjiang Province Education Department Ordinary College Young Talents Training Project(UNPYSCT-2018126); Heilongjiang government, post-doc program(LBH-Z20162);Harbin university of commerce $\mathrm{PhD}$ research startup fund(2019DS002); Youth innovative talent project Harbin university of commerce(2020CX21).

\section{References}

1. W.Louis. Urbanism as a Way of Life. Amer. J. sociol, 44(1938)

2. A. Sen, Collective Choice and Social Welfare. San Francisco : Holden-Day,North-Holland (1970)

3. D. Belanche, LV Casaló, M. Rubio. Local place identity: A comparison between residents of rural and urban communities. J. Rural. Stud, 82(2021)

4. J. Faguet. Does decentralization increase government responsiveness to local needs? : Evidence from Bolivia. J. Public. Econ, 88(2004)

5. M.lipton. Urban bias: Consequences, class and causality. J. Dev. Stud, 29(1993) 